\title{
Multiple Choice Questions in Intensive Care Medicine
}

\author{
Steve Benington (Author), Peter Nightingale (Editor), Maire Shelly (Editor). TFM \\ Publishing Limited, UK, 2009, \$59.95 Can, 276 pages, ISBN: 9781903378649
}

\author{
Sherissa Microys, MD
}

Published online: 26 September 2009

(C) Canadian Anesthesiologists' Society 2009

\begin{abstract}
Multiple Choice Questions in Intensive Care Medicine is written by Dr. Steve Benington, a physician who recently sat the European Diploma in Intensive Care (EDIC) examination in the United Kingdom. Furthermore, the book is edited by two EDIC examiners. Dr. Benington laments that there were no available books during his study and review to help him prepare for the Multiple Choice Questions (MCQ) portion of the EDIC exam. Hence this book, which is dedicated to assist trainees in intensive care programs and to serve as an aid for caregivers of critically ill patients.
\end{abstract}

The book begins with an explanation on how best it should be used. The MCQ section of the EDIC includes 50 "Type A" questions where the single best answer is chosen and 50 "Type $\mathrm{K}$ " questions, each with four branches, where either a true or false response is selected from each branch. Usually three hours are allotted for the 100 questions. The book is divided into three sections and in essence provides three sample exams. Following each 100question paper, answers are provided with brief explanations and supporting references.

Although this book was written with its primary focus on the UK trainee, it certainly has its merit for critical care trainees and educators in Canada and elsewhere. A considerable scope of topics are evaluated in the book, including resuscitation, diagnosis, disease management, perioperative care, organ support, applied basic science and ethical issues.

It is useful that most of the laboratory values that appear are in both Système International (SI) units and American National Institute of Standards and Technology units,

S. Microys, MD $(\bowtie)$

Ottawa Hospital, University of Ottawa, Ottawa, Canada

e-mail: smicroys@ottawahospital.on.ca however all units of pressure are expressed in kilopascals rather than $\mathrm{mmHg}$ which may not be as familiar to the Canadian reader. Similarly, there are some references to British standards and guidelines that are not always identical to Canadian guidelines.

At this time, the format of the Royal College of Physicians and Surgeons of Canada examination in Critical Care Medicine encompasses only short-answer questions. However, many programs use multiple choice tests to focus learning during postgraduate training and for in-training evaluations. Accordingly, this book could serve as an independent study resource for students and residents to assess their knowledge, and educators could use this book in the classroom to lead discussions on a variety of critical care topics. If nothing else, it serves as a good basis of reference for many of the important review articles, reference textbooks, and landmark papers that have moulded our current thinking and approach in critical care today.

There are two other texts that are designed primarily as reviews and examination preparation guides in critical care medicine: Critical Care Study Guide: Text and Review by Gerard J. Criner was published in 2002; and Critical Care Medicine Review and Self-Assessment by Joseph Parrillo was published in 2005. Both of these books are targeted towards an American audience and preparation for United States Board certification. A definite advantage of Benington's book is the fact that it is the most current text of its type within a specialty that seems to evolve on a daily basis.

However, one disadvantage of this book is the random nature of the contents of the questions, which does not entice the reader to search specific topics in more detail. Furthermore, the book does not provide an index or a separate list of the references. This issue should be considered for future editions. It is helpful to understand how 
examiners prepare multiple choice questions, as "the devil is in the details". This provides insight into the approach used to create and word MCQs and directs the reader's thinking and awareness towards details in critical care medicine that are often underappreciated.
In summary, Multiple Choice Questions in Intensive Care Medicine is a useful resource tool to lead independent or group study in critical care medicine and to assist in the preparation for qualifying examinations within the specialty. 